\section{SOI: $1.1 /$ TAS DOI: $10.15863 /$ TAS International Scientific Journal Theoretical \& Applied Science}

p-ISSN: 2308-4944 (print) e-ISSN: 2409-0085 (online)

Year: 2018 Issue: 09 Volume: 65

Published: 24.09.2018 http://T-Science.org
Hafiz Muhammad Ayyaz Afzal Post graduate Resident in Nishter Hospital Multan,

Pakistan.

doctorayyaz9@gmail.com

Verda Zulfiqar

Doctor in Jinnah Hospital Lahore, Pakistan shahryar095@gmail.com

Hira Liaqat

WMO at THQ Pasrur district Sialkot Pakistan. baskketbella@gmail.com

\title{
MANAGEMENT OF T.B SPINE WITH ANTERIOR CAGE FIXATION AND OUTCOME
}

\begin{abstract}
Objective: To find out role of anterior cage fixation in management of tuberculosis of dorsal spine and its outcome.

Study Design and Duration: This is a prospective study completed in duration of 12 months from June 2017 to May 2018.

Setting: This study was done in a tertiary care hospital, Khyber Teaching Hospital Peshawar, Pakistan.

Patients and Methods: Patients presented to the study hospital with spinal tuberculosis were included in this study. Diagnosis was established on the basis of history, examination, X-ray and MRI spine. Additional investigations were also done to support diagnosis such as CBC with ESR and histological examination of biopsy after surgery confirmed the diagnosis. Patients were told about the disease severity and its possible management options either conservative or surgical and they were also informed about the outcome of each option. Patients, who refused surgery, were excluded from the study. Such cases were managed conservatively. A written informed consent taken from all patients before surgery and additional consent was also taken for including their data in the study. Permission was taken from ethical committee of the hospital for conducting study. These cases were admitted in the neurosurgical ward of the study hospital. After getting all investigations and anesthesia fitness they were prepared for surgery. Hospital stay of these patients was 7-15 days. In these cases anterior spinal decompression done and internal fixation using cage was performed. All data collected was analyzed and results presented in tabular forms and using graphs.

Results: Total 53 cases were selected for the study initially and 3 cases refused surgical management so they were excluded and 50 cases were operated. Frankle grading system was used for determining severity of disease and deciding management plan accordingly. According to this system 18 cases were having grade-A, 9 cases with grade- $B, 10$ cases had grade- $C, 8$ cases with grade-D and 5 cases were having grade- $E$. Age range was 10-74 years with mean age of 43 years. There were $56 \%$ male and $44 \%$ female cases. $16 \%$ cases were having age 10-20 years, $30 \%$ with $21-30$ years, $18 \%$ with $31-40$ years, $8 \%$ with $41-50$ years, $12 \%$ with $51-60$ years, $10 \%$ between 61 70 years and $6 \%$ cases were above 70 years of age. Out of 50 cases 42 were operated having neurological deficit.

Conclusion: Anterior spine decompression and internal fixation with cage is a procedure of choice in the management of dorsal spinal tuberculosis. This procedure is associated with some complications but overall success rate is high.
\end{abstract}

Key words: Spinal tuberculosis, Internal spinal fixation, Anterior cage fixation, Pots disease, Carries spine.

Language: English

Citation: Ayyaz Afzal HM, Zulfiqar V, Liaqat H (2018) MANAGEMENT OF T.B SPINE WITH ANTERIOR CAGE FIXATION AND OUTCOME. ISJ Theoretical \& Applied Science, 09 (65): 139-143.

Soi: http://s-o-i.org/1.1/TAS-09-65-22 Doi: crossef https://dx.doi.org/10.15863/TAS.2018.09.65.22

\section{INTRODUCTION}

Tuberculosis is a disease of ancient times. It may involve any body part skin, lungs, brain, bones and intestines. This is considered a disease most prevalent among people with low socioeconomic status and so found mostly in underdeveloped countries. Asian countries being among developing and underdeveloped countries also have high incidence of this disease. When it involves dorsal spine it is called pots disease. In this disease patients present with kyphosis, back pain, lordosis, and decreased stability of spine, neurological deficit below lesion, fever and weight loss. This is a chronic disease with progressively increasing pathologies. This can be diagnosed by taking history, physical examination, CT scan and MRI spine and 
histological examination of biopsy. Patients presented to the study hospital with spinal tuberculosis were included in this study. Diagnosis was established on the basis of history, examination, $\mathrm{X}$-ray and MRI spine. Additional investigations were also done to support diagnosis such as CBC with ESR and histological examination of biopsy after surgery confirmed the diagnosis. Patients were told about the disease severity and its possible management options either conservative or surgical and they were also informed about the outcome of each option. In this disease erythrocyte sedimentation rate is increased. This may involve anterior and posterior parts of vertebrae but anterior involvement is more complicated and common. As a treatment anterior decompression of vertebrae is done and internal fixation is done by applying cage anteriorly. Complications of procedure may be hemorrhage, improper fixation, and breakage of screws or loosening of screws, instability, and compression fracture of adjacent vertebrae or discitis of adjacent vertebrae. Infectious part of vertebrae is debrided and defect is filled with bone graft from iliac crest or fibula. Cage being used in this operation is made of titanium which is an inert material having much strength. Cage fixation just provides stability to the spine and does not improve neurological deficite. These patients are given treatment with antituberculous drugs for 18 months.

\section{Patients and Methods}

This is a prospective study conducted on cases with pots disease presented in neurosurgical outpatient door of the study hospital during study period of one year. These cases presented either directly to the hospital or were referred from other hospitals and some of them were taking some sort of medical treatment from few months already without any relieve.Patients presented to the study hospital with spinal tuberculosis were included in this study. Diagnosis was established on the basis of history, examination, X-ray and MRI spine. Additional investigations were also done to support diagnosis such as CBC with ESR and histological examination of biopsy after surgery confirmed the diagnosis. Patients were told about the disease severity and its possible management options either conservative or surgical and they were also informed about the outcome of each option. Patients, who refused surgery, were excluded from the study. Such cases were managed conservatively. A written informed consent taken from all patients before surgery and additional consent was also taken for including their data in the study. Permission was taken from ethical committee of the hospital for conducting study. These cases were admitted in the neurosurgical ward of the study hospital. After getting all investigations and anesthesia fitness they were prepared for surgery. Hospital stay of these patients was 7-15 days. In these cases anterior spinal decompression done and internal fixation using cage was performed. All data collected was analyzed and results presented in tabular forms and using graphs. Patients having spinal tumors or spinal tuberculosis involving posterior part of vertebrae were not involved in this study.

\section{Results}

Patients presented to the study hospital with spinal tuberculosis were included in this study. Diagnosis was established on the basis of history, examination, X-ray and MRI spine. Additional investigations were also done to support diagnosis such as CBC with ESR and histological examination of biopsy after surgery confirmed the diagnosis. Total 53 cases were selected for the study initially and 3 cases refused surgical management so they were excluded and 50 cases were operated. Frankle grading system was used for determining severity of disease and deciding management plan accordingly. According to this system 18 cases were having grade-A, 9 cases with grade-B, 10 cases had grade-C, 8 cases with grade-D and 5 cases were having gradeE. Age range was 10-74 years with mean age of 43 years. There were $28(56 \%)$ male and $22(44 \%)$ female cases. $8(16 \%)$ cases were having age $10-20$ years, $15(30 \%)$ with $21-30$ years, $9(18 \%)$ with $31-40$ years, $4(8 \%)$ with $41-50$ years, $6(12 \%)$ with $51-60$ years, $5(10 \%)$ between $61-70$ years and $3(6 \%)$ cases were above 70 years of age. Out of 50 cases 42 were operated having neurological deficit. Complications related to the procedure were reported in $9(18 \%)$ cases with wound infection in $3(6 \%)$ cases, dyspnea in 2(4\%) cases, neurodeficit in one case. Compression fracture in $1(2 \%)$ and discitis of adjacent vertebrae was reported in $1(2 \%)$ cases. While post operative correction loss reported in one (2\%) case. 


\begin{tabular}{|c|c|c|c|c|c|c|}
\hline Impact Factor: & $\begin{array}{l}\text { ISRA (India) } \\
\text { ISI (Dubai, UAE } \\
\text { GIF (Australia) } \\
\text { JIF }\end{array}$ & $\begin{array}{r}=1.344 \\
=0.829 \\
=0.564 \\
=1.500\end{array}$ & $\begin{array}{l}\text { SIS (USA) } \\
\text { PИНЦ (Russia) } \\
\text { ESJI (KZ) } \\
\text { SJIF (Morocco) }\end{array}$ & $\begin{array}{l}=0.912 \\
=0.156 \\
=4.102 \\
=2.031\end{array}$ & $\begin{array}{l}\text { ICV (Poland) } \\
\text { PIF (India) } \\
\text { IBI (India) }\end{array}$ & $\begin{array}{l}=6.630 \\
=1.940 \\
=4.260\end{array}$ \\
\hline
\end{tabular}

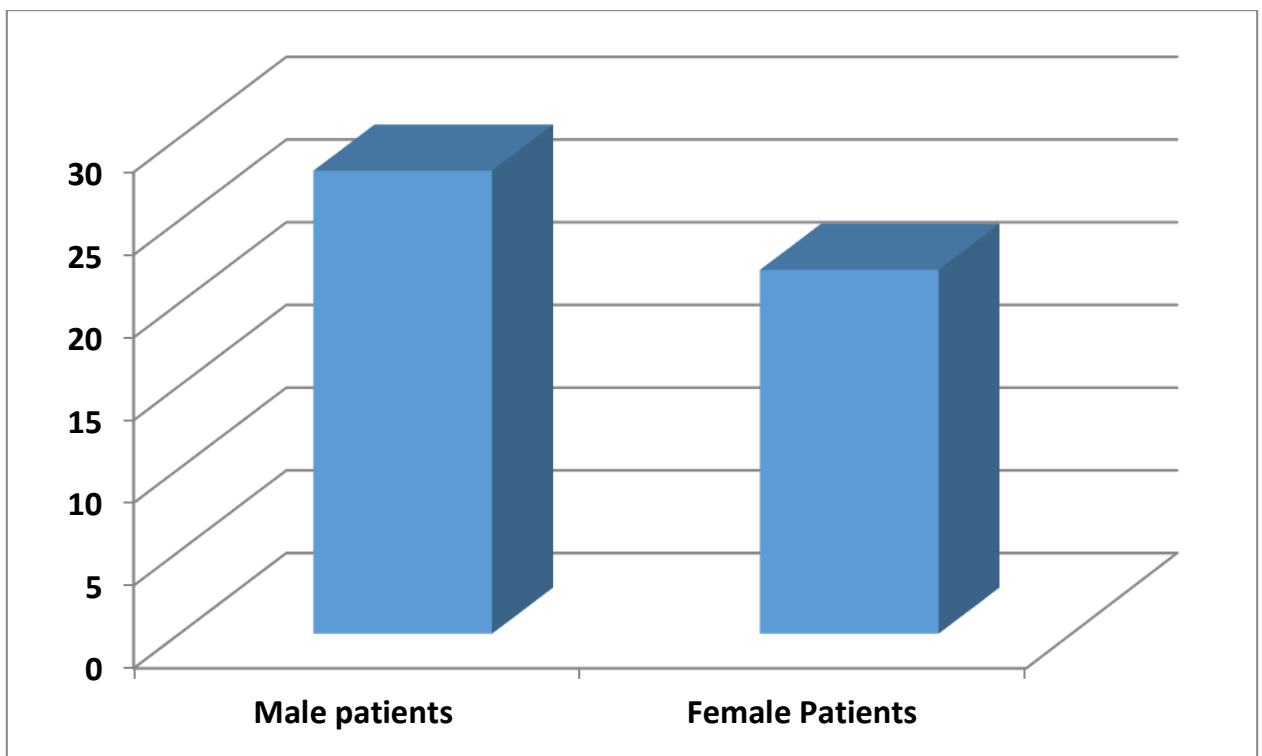

Figure-1 Gender distribution of patients with T.B spine in study group

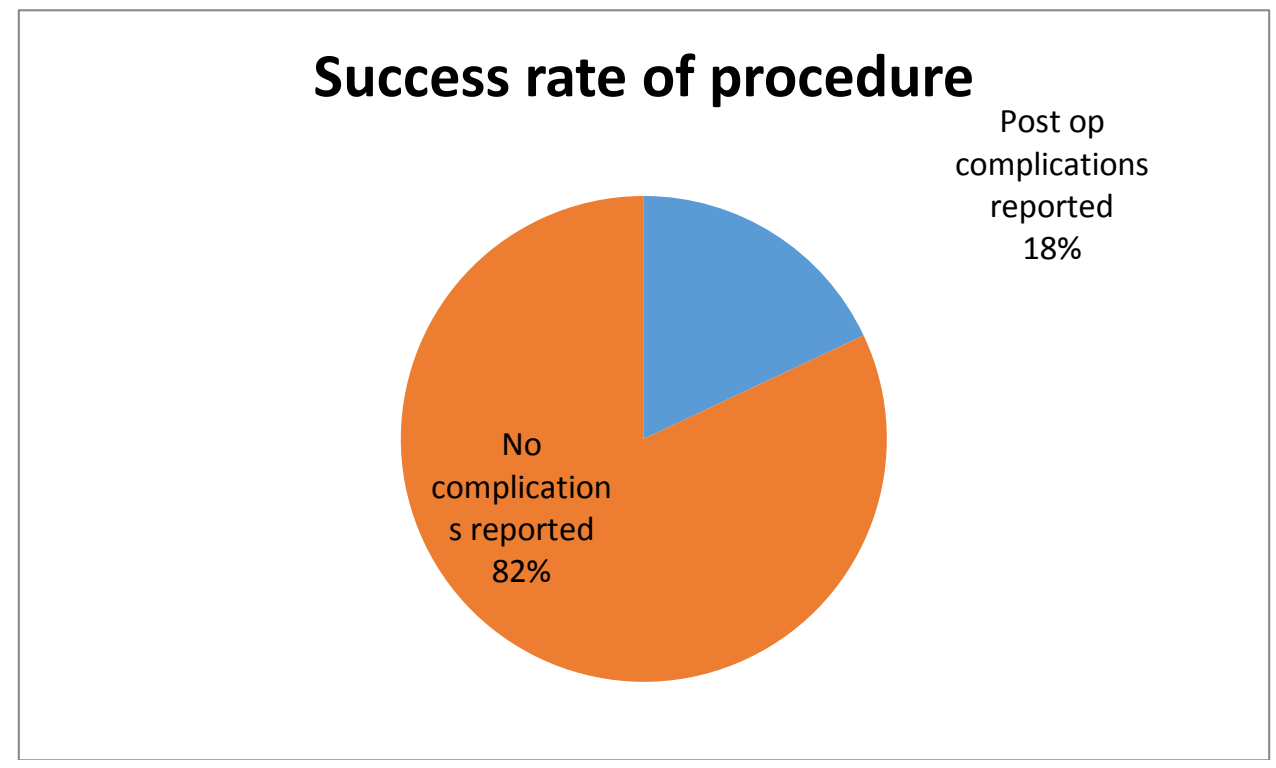

Post operative complications among patients in study group

Table-1

\begin{tabular}{|l|c|c|}
\hline \multicolumn{1}{|c|}{ Post operative complications } & N & \% \\
\hline Wound infection & 3 & 6 \\
\hline Dyspnea & 2 & 2.6 \\
\hline Correction loss & 1 & 2 \\
\hline Neurodeficit & 1 & 2 \\
\hline $\begin{array}{l}\text { Compression Fx of adjacent } \\
\text { vertebrae }\end{array}$ & 1 & 2 \\
\hline Discitis of adjacent Vetebrae & 1 & 2 \\
\hline Total & $\mathbf{9}$ & $\mathbf{1 8}$ \\
\hline
\end{tabular}


Age distribution of patients in study group

\begin{tabular}{|c|c|c|}
\hline Age of patients (years) & Number of Patients & \% \\
\hline $10-20$ & 8 & 16 \\
\hline $21-30$ & 15 & 30 \\
\hline $31-40$ & 9 & 18 \\
\hline $41-50$ & 4 & 8 \\
\hline $51-60$ & 6 & 12 \\
\hline $61-70$ & 5 & 10 \\
\hline Above 70 & 3 & 6 \\
\hline Total & $\mathbf{5 0}$ & $\mathbf{1 0 0}$ \\
\hline
\end{tabular}

\section{DISCUSSION}

Tuberculosis is a very common chronic disease which may involve any system of the body. In skeletal system it mainly involves vertebrae. Anterior vertebral involvement causes more instability of spine as compared to posterior involvement. Consequences of this are kyphosis and reduced neurological functions below the lesion. Sensory impairment is not major problem but motor functions deficit causes more problem. Tuberculosis is a disease of ancient times. It may involve any body part skin, lungs, brain, bones and intestines. This is considered a disease most prevalent among people with low socioeconomic status and so found mostly in underdeveloped countries. Asian countries being among developing and underdeveloped countries also have high incidence of this disease. When it involves dorsal spine it is called pots disease. In this disease patients present with kyphosis, back pain, lordosis, and decreased stability of spine, neurological deficit below lesion, fever and weight loss. This is a chronic disease with progressively increasing pathologies. Total 53 cases were selected for the study initially and 3 cases refused surgical management so they were excluded and 50 cases were operated. Frankle grading system was used for determining severity of disease and deciding management plan accordingly. According to this system 18 cases were having grade-A, 9 cases with grade- $\mathrm{B}, 10$ cases had grade- $\mathrm{C}, 8$ cases with grade-D and 5 cases were having grade-E. Diagnosis was established on the basis of history, examination, Xray and MRI spine. Additional investigations were also done to support diagnosis such as CBC with ESR and histological examination of biopsy after surgery confirmed the diagnosis. Patients were told about the disease severity and its possible management options either conservative or surgical and they were also informed about the outcome of each option. Patients, who refused surgery, were excluded from the study. Such cases were managed conservatively. A written informed consent taken from all patients before surgery and additional consent was also taken for including their data in the study. . Complications related to the procedure were reported in $9(18 \%)$ cases with wound infection in $3(6 \%)$ cases, dyspnea in $2(4 \%)$ cases, neurodeficit in one case. Compression fracture in $1(2 \%)$ and discitis of adjacent vertebrae was reported in $1(2 \%)$ cases. . Infectious part of vertebrae is debrided and defect is filled with bone graft from iliac crest or fibula. Cage being used in this operation is made of titanium which is an inert material having much strength. Cage fixation just provides stability to the spine and does not improve neurological deficite. These patients are given treatment with antituberculous drugs for 18 months. According to a study done by Gabriel one case reported with post operative brown squared syndrome with sensory neural deficit below lesion.

\section{Conclusion}

Tuberculosis of dorsal spine causes more morbidity and associated with neurological deficit below lesion. Anterior spine decompression and internal fixation with cage is a procedure of choice in the management of dorsal spinal tuberculosis. This procedure is associated with some complications but overall success rate is high. Early stabilization of the spine may secure neurological functions and morbidity and disability can be reduced. 


\begin{tabular}{l|lr|ll|ll} 
& ISRA (India) & $=\mathbf{1 . 3 4 4}$ & SIS (USA) & $=\mathbf{0 . 9 1 2}$ & ICV (Poland) & $=\mathbf{6 . 6 3 0}$ \\
Impact Factor: & ISI (Dubai, UAE) $=\mathbf{0 . 8 2 9}$ & PUHЦ (Russia) $=\mathbf{0 . 1 5 6}$ & PIF (India) & $=\mathbf{1 . 9 4 0}$ \\
& GIF (Australia) & $=\mathbf{0 . 5 6 4}$ & ESJI (KZ) & $=\mathbf{4 . 1 0 2}$ & IBI (India) & $=\mathbf{4 . 2 6 0}$ \\
& JIF & $=\mathbf{1 . 5 0 0}$ & SJIF (Morocco) $=\mathbf{2 . 0 3 1}$ & & \\
\hline
\end{tabular}

\section{References:}

1. Ali M, Khan HM, Khanzada K, Usman M, Hussain R, Rehman ZU. (2012) Level of spinal involvement in patients operated for spinal tuberculosis. J Postgrad Med Inst 2012; 26 (4): 439-43.

2. Davidson PT, Le HQ. (1999) Tuberculosis and nontuberculous mycobacterial infections. In: Schlossberg D, ed. musculoskeletal tuberculosis. 4th ed. Saint Louis, MO: W B Saunders; 1999: 204-20.

3. Arshad M. (2012) Role ofsurgery in the management of Carrie's spine. Pak. J. of Neurol. Surg 2012; 16 (1): 36-40.

4. Park DW, Sohn JW, Kim EH, et al. (2007) outcome and management of spinal tuberculosis according to the severity of disease: a retrospective study of 137 adult patients at Korean teaching hospital. Spine 2007; 32 (4) E 103-5.

5. Ozdemir HM, Us AK, O?ün T. (2003) The role of anterior spinal instrumentation and allograft fibula for the treatment of pott disease. Spine (Phila Pa 1976) 2003;28:474-79.

6. Singh S, Kumaraswamy V, Sharma N, Saraf SK, and Khare GN. (2012) Evaluation of Role of Anterior Debridement and Decompression of Spinal Cord and Instrumentation in Treatment of Tubercular Spondylitis.Asian Spine J. 2012 September; 6(3): 183-193.

7. Garg B, Kandwal P, BidreNagaraja UB, Goswami A, and Jayaswal A. (2012) Anterior versus posterior procedure for surgical treatment of thoracolumbar tuberculosis: A retrospective analysis.Indian J Orthop. 2012; 46(2): 165-70.

8. Tuli SM. (2007) Tuberculosis of the Spine: A Historical Review. Clin Orthop Relat Res. 2007;460:29

9. Odgson AR, Stock FE, Fang HS, Ong GB. (1960) Anterior spinal fusion: The operative approach and pathological findings in 412 patients with Pott's disease of the spine. $\mathrm{Br} \mathbf{J}$ Surg. 1960;48:172

10. Chen CL, Chou CW, Su WW, Cheng CY, Yu CT. (1976) Dislodged upper thoracic cage in the gastrointestinal tract: a case report and literature reviews. Spine (Phila $\mathrm{Pa}$ 1976) 2008;33:E802 - E806 .

11. Korovessis P, Petsinis G, Koureas G, Iliopoulos P, Zacharatos S. (2006) Anterior surgery with insertion of titanium mesh cage and posterior instrumented fusion performed sequentially on the same day under one anesthesia for septic spondylitis of thoracolumbar spine: is the use of titanium mesh cages safe? Spine (Phila $\mathrm{Pa}$ 1976) 2006;31:1014-19.

12. Sundararaj G D, Amritanand A,Venkatesh K (2011) Arockiaraj The Use of Titanium Mesh Cages in the Reconstruction of Anterior Column Defects in Active Spinal Infections: Can We Rest the Crest?.Asian Spine J. 2011; 5(3): 155-161.

13. Robinson Y, Tschoeke SK, Kayser R, Boehm H, Heyde CE. (2009) Reconstruction of large defects in vertebral osteomyelitis with expandable titanium cages. IntOrthop. 2009;33:745-49.

14. Fayazi AH, Ludwig SC, Dabbah M, Bryan Butler R, Gelb DE. (2004) Preliminary results of staged anterior debridement and reconstruction using titanium mesh cages in the treatment of thoracolumbar vertebral osteomyelitis. Spine J. 2004;4:388-95.

15. Sundararaj GD, Behera S, Ravi V, Venkatesh K, Cherian VM, Lee V. (2003) Role of posterior stabilisation in the management of tuberculosis of the dorsal and lumbar spine. J Bone Joint Surg Br. 2003 Jan; 85(1):100-6.

16. Sundararaj GD, Babu N, Amritanand R, et al. (2007) Treatment of haematogenous pyogenic vertebral osteomyelitis by single-stage anterior debridement, grafting of the defect and posterior instrumentation. J Bone Joint Surg Br. 2007;89:1201-1205.

17. Benli IT, Alanay A, Akalin S, et al. (2004) Comparison of anterior instrumentation systems and the results of minimum 5 years follow-up in the treatment of tuberculosis spondylitis. Kobe J Med Sci. 2004;50:167-80.

18. Slucky AV, Eismont FJ. (1997) Spinal infections. In: Bridwell KH, Dewald RL, editors. The textbook of spinal surgery. Philadelphia: Lippincott; 1997. pp. 2141-83.

19. Tuli SM. Severe kyphotic deformity in tuberculosis of the spine. IntOrthop. 1995;19:327-31.

20. Liu ZX, Zhu H, Qi QL, Liu J. (2010) Analysis of the curative effect of 162 cases of thoracic and lumbar tuberculosis. ZhongguoGu Shang . $2010 \mathrm{Jul} ; 23(7): 497-9$. 